\title{
Apremilast in refractory orogenital ulcers and other manifestations of Behçet's disease. National multicenter study of 51 cases in clinical practice.
}

\section{Belén Atienza-Mateo}

Hospital Universitario Marques de Valdecilla

José Luis Martín-Varillas

Hospital Universitario Marques de Valdecilla

Jenaro Graña

Complexo Hospitalario Universitario A Coruna

\section{Gerard Espinosa}

Hospital Clinic de Barcelona

\section{Clara Moriano}

Complejo Asistencial Universitario de Leon

\section{Trinidad Pérez-Sandoval}

Complejo Asistencial Universitario de Leon

Manuel Martín-Martínez

Complejo Asistencial Universitario de Leon

Elvira Díez-Álvarez

Complejo Asistencial Universitario de Leon

María Dolores García-Armario

Hospital Lluis Alcanyis de Xativa

\section{Esperanza Martínez}

Hospital Lluis Alcanyis de Xativa

Iván Castellví

Hospital de la Santa Creu i Sant Pau

\section{Francisca Sivera}

Hospital General de Elda

Jaime Calvo-Alen

Hospital Universitario Araba

\section{Isabel de la Morena}

Consorci Hospital General Universitari de Valencia

\section{Francisco Ortiz-Sanjuán}

Hospital Universitari i Politecnic La Fe

José Andrés Román-Ivorra 
Hospital Universitari i Politecnic La Fe

\section{Ana Pérez-Gómez}

Hospital Universitario Principe de Asturias

\section{Sergi Heredia}

Hospital Universitari Germans Trias i Pujol

\section{Alejandro Olivé}

Hospital Universitari Germans Trias i Pujol

Águeda Prior-Español

Hospital Universitari Germans Trias i Pujol

\section{Carolina Díez}

Hospital del Bierzo

Juan José Alegre

Hospital Universitario Doctor Peset

Amparo Ybáñez

Hospital Universitario Doctor Peset

\section{Angels Martinez-Ferrer}

Hospital Universitario Doctor Peset

Javier Narváez

Hospital Universitari de Bellvitge

Ignasi Figueras

Hospital Universitari de Bellvitge

\section{Ana Isabel Turrión}

Hospital Universitario de Salamanca

\section{Susana Romero-Yuste}

Complejo Hospitalario Universitario de Pontevedra

\section{Pilar Trénor}

Hospital Clínico Universitario de Valencia

\section{Soledad Ojeda}

Hospital Universitario de Gran Canaria Dr Negrin

Inmaculada Ros

Hospital Son Llatzer

Javier Loricera

Hospital Universitario Marques de Valdecilla

\section{Vanesa Calvo-Río}

Hospital Universitario Marques de Valdecilla

\section{Carmen González-Vela}

Hospital Universitario Marques de Valdecilla

\section{Santos Castañeda}

Hospital Universitario de la Princesa 
José L. Hernández

Hospital Universitario Marques de Valdecilla

Miguel A. Gonzalez-Gay

Hospital Universitario Marques de Valdecilla

Ricardo Blanco ( $\square$ rblancovela@gmail.com )

Hospital Universitario Marques de Valdecilla https://orcid.org/0000-0003-2344-2285

\section{Research article}

Keywords: Apremilast, Behçet's disease, Oral ulcers, Genital ulcers, Multicenter study

Posted Date: May 7th, 2020

DOI: https://doi.org/10.21203/rs.3.rs-25996/v1

License: (c) (i) This work is licensed under a Creative Commons Attribution 4.0 International License.

Read Full License 


\section{Abstract \\ Background}

Oral and/or genital aphthous ulcers are the most common symptoms of Behçet's disease (BD), and are often refractory to conventional treatment. The inhibitor of phosphodiesterase- 4 apremilast (APR) has demonstrated efficacy in the treatment of this manifestations. The objective of the present study was to assess the efficacy of APR in the management of refractory oral and/or genital ulcers in patients with BD.

\section{Methods}

National multicenter open-label observational study on BD patients with recurrent oral and/or genital ulcers. In all cases orogenital ulcers were refractory to conventional therapy. APR was given and maintained at standard dose of $30 \mathrm{mg}$ twice daily. The main outcome was the achievement of oral and/or genital ulcers remission. Efficacy of APR for other clinical manifestations was also evaluated.

\section{Results}

We included 51 patients ( 35 women/16 men; mean age $44.7 \pm 13.2$ years). Before APR, all patients had received several systemic conventional and/or biologic drugs. APR was initiated because of refractory oral $(n=19)$ or genital $(n=2)$ aphthous ulcers or both $(n=30)$. Other manifestations found at APR onset were arthralgia/arthritis $(n=16)$, folliculitis/pseudofolliculitis $(n=14)$, erythema nodosum $(n=3)$, furunculosis $(n=2)$, paradoxical psoriasis induced by TNFa-inhibitors $(n=2)$, ileitis $(n=2)$, deep venous thrombosis $(n=2)$, leg ulcers $(n=1)$, erythematosus and scaly skin lesions $(n=1)$, fever $(n=1)$, unilateral anterior uveitis $(n=1)$ and neurobehçet $(n=1)$. After a mean follow-up of $8.5 \pm 6.9$ months, most patients had experienced improvement of orogenital ulcers and prednisone dose had been successfully reduced or discontinued. APR also yielded improvement of some non-aphthous manifestations such as the cutaneous follicular and intestinal manifestations. However, the effect on musculoskeletal manifestations was variable.

\section{Conclusion}

APR yielded a rapid and maintained improvement of refractory mucocutaneous ulcers of BD, even in patients refractory to several systemic drugs including biologic therapy.

\section{Background}

Behçet's disease (BD) is a chronic systemic inflammatory disorder of unknown etiology included in the group of variable vessel vasculitis [1, 2]. It is characterized by a wide range of heterogeneous clinical manifestations and the treatment depends mainly on the clinical severity and affected organs $[3,4]$. 
Major organ involvement such as ocular, neurologic, vascular and gastrointestinal disease often requires an aggressive approach, usually with immunosuppressive agents [5, 6]. Although recurrent oral and/or genital ulcers are not life-threatening complications, they are one of the most characteristic features of BD. Moreover, they can be extremely painful and disabling, $[7,8]$. Several systemic therapeutic agents such as colchicine, glucocorticoids, conventional and biologic immunosuppressive drugs have been used for orogenital aphthous ulcers with contradictory and variable results [9].

Apremilast (APR) is an orally active small molecule which inhibits phosphodiesterase-4 (PDE-4). APR modulates intracellular inflammatory pathways decreasing proinflammatory and increasing antiinflammatory mediators $[10,11]$. This drug is included in the group of targeted synthetic diseasemodifying antirheumatic drugs (tsDMARDs). Although combination therapy with two biological diseasemodifying antirheumatic drugs (bDMARDs) is generally not recommended [12], APR may be used in monotherapy or combined with either conventional synthetic disease-modifying antirheumatic drugs (csDMARDs) and/or bDMARDs.

Randomized clinical trials (RCTs) are conducted under highly standardized design with strict inclusion criteria, excluding some real-world patients and special situations to make the statistical assessment of efficacy and/or safety more efficient [13]. Because of that, features of RCTs may differ from those of clinical practice, which could influence the results of the treatment [14]. Two randomized double-blinded phase II and III clinical trials have shown efficacy and safety of APR for oral ulcers of BD $[15,16]$. Based on these trials, the U. S. Food and Drug Administration (FDA) has recently approved APR for the treatment of oral ulcers associated with BD (www.fda.gov). However, in these trials, patients with active involvement of any major organ during the 12 months before recruitment, history of recurrent or chronic infections, latent tuberculosis or who had received biologic therapies were not included. Furthermore, patients were not allowed to receive concomitant medications indicated for the management of BD. Full information related to orogenital ulcers prior to APR onset was not available in these two trials. Moreover, follow-up was of only 28 weeks and the efficacy of APR for manifestations different from orogenital ulcers was not reported.

Taking into account all these considerations, the aim of the present study was to assess the efficacy of APR for orogenital ulcers, either combined or in monotherapy, in a National multicenter clinical practice study of BD patients with orogenital ulcers refractory to conventional treatment. Moreover, the efficacy of APR for other clinical manifestations was also evaluated.

\section{Methods}

\section{Design and Enrollment Criteria}

We performed a multicenter open-label observational study that encompassed 51 BD patients with refractory mucocutaneous ulcers. Besides topical treatment, oral colchicine, non-steroidal anti- 
inflammatory drugs (NSAIDs) and systemic glucocorticoids, patients had received at least one csDMARD and in most cases bDMARD before the onset of APR.

Patients were diagnosed with BD at the Rheumatology, Autoimmune Diseases or Dermatology Units of 20 referral Spanish hospitals. The study was approved by the Clinical Research Ethics Committee. APR was prescribed as an off-label indication and, therefore, written informed consent was also requested and obtained from all patients.

BD diagnosis was performed according to the International Study Group for BD (ISGBD) criteria reported in 1990 [17]. As indicated by the Spanish National Guidelines for bDMARDs and tsDMARDs in Rheumatology [18-22], infections as well as malignancies were ruled out before starting the treatment. APR was initiated using dose escalation until reaching a maintenance dose of $30 \mathrm{mg}$ twice daily.

\section{Data Collection}

Data were gathered from the clinical records of the patients according to a specific designed protocol that included clinical and laboratory data, diagnosis, pharmacological agents used for the treatment of BD, response to APR and development of side effects. Data were reviewed for confirmation and stored in a computerized database. To minimize entry error, all the data were double checked.

\section{Outcome Variables, Clinical Definitions And Laboratory Data}

The primary outcome variable was the efficacy of APR to achieve remission of oral and/or genital ulcers. For this purpose, we assessed remission and flares of oral and/or genital ulcers. Complete remission was considered as the disappearance of ulcers while partial remission was defined as the reduction of at least $50 \%$ in the number of ulcers and/or a reduction in the number of flares. Flare was defined as the recurrence of ulcers when complete remission was achieved for at least one month. Similar definitions (complete remission, partial remission and flare) were applied when we assessed the effect of APR other clinical manifestations.

We also assessed safety and retention rate of APR as well as the sparing glucocorticoid effect due to the use of this molecule.

Serum C-reactive protein (CRP) levels and erythrocyte sedimentation rate (ESR), full blood cell count, liver and renal function tests were also analyzed. ESR values higher than 20 or $25 \mathrm{~mm} / 1$ st hour for men or women, respectively, and those of serum CRP greater than $0.5 \mathrm{mg} / \mathrm{dL}$ were considered raised.

Outcome variables were recorded in most patients at baseline (APR onset) and in every visit at 1-2 weeks, 4 weeks, 3 months, 6 months, 12 months, 18 months and 24 months. These visits were performed in each individual center following a pre-established protocol agreed by the investigators of this collaborative study. 
An additional subanalysis considering APR in monotherapy or combined with bDMARDs and csDMARDs was also performed.

Adverse events related to APR treatment were evaluated, recorded and stored in a specific file designed for this purpose.

\section{Statistical Analysis}

Results were expressed as mean \pm standard deviation (SD) for variables with a normal distribution, or as median and interquartile range (IQR) [25th -75th IQR] for those not normally distributed. The effect of APR was assessed on clinical symptoms, serum CRP and ESR values and on daily glucocorticoid dose required. Comparisons were performed at baseline, 1-2 weeks, 4 weeks, 3 months, 6 months, 12 months, 18 months and 24 months using the Wilcoxon's signed rank test. In addition, clinical and laboratory data of last visit were also assessed. Statistical significance was considered as a p-value $\leq 0.05$. Statistical analysis was performed with the STATISTICA software (StatSoft, Tulsa, OK, USA).

\section{Results}

\section{Demographic and general data at apremilast onset}

A series of 51 patients ( 35 women/16 men) diagnosed with BD and treated with APR was evaluated. The mean \pm SD age at APR onset was $44.7 \pm 13.2$ years. HLA-B51 was positive in 20 patients $(39.2 \%)$, negative in $27(52.9 \%)$ and data were not available in another 4 cases $(7.9 \%)$. The median [IQR] time from the diagnosis of BD to APR onset was 48 [23-120] months.

APR was initiated because severe and refractory oral $(n=19)$, genital $(n=2)$ aphthous ulcers or both $(n=$ 30). Other active manifestations present at APR onset were arthralgia/arthritis ( $n=16 /$ clinically evident synovitis in 5 of them), folliculitis/pseudofolliculitis $(n=14)$, erythema nodosum $(n=3)$, furunculosis $(n=$ 2), paradoxical psoriasis induced by TNFa-inhibitors (TNFi) $(n=2)$, ileitis $(n=2)$, deep venous thrombosis $(n=2)$, leg ulcers $(n=1)$, erythematosus and scaly skin lesions $(n=1)$, fever $(n=1)$, unilateral anterior uveitis $(n=1)$ and neurobehçet $(n=1)$. Elevation of acute phase reactants was observed in 24 patients (CRP in 23 and/or ESR in 11). Table 1 summarizes the main general and clinical features at baseline and at the end of the follow-up. 
Table 1

Features and follow-up of 51 patients with Behçet's disease refractory mucocutaneous ulcers undergoing apremilast therapy.

\begin{tabular}{|c|c|}
\hline Number of patients (n) & 51 \\
\hline Age, mean (SD) years & $44.7(13.2)$ \\
\hline Sex, men/women, n/n & $16 / 35$ \\
\hline Months from diagnosis of BD to APR onset & $48[23-120]$ \\
\hline Main clinical symptoms for starting APR, $n(\%)$ & $19(37.2)$ \\
\hline Oral ulcers & $2(3.9)$ \\
\hline Genital ulcers & $30(58.9)$ \\
\hline \multicolumn{2}{|l|}{ Oral and genital ulcers } \\
\hline Other symptoms at APR onset, $n$ & 34 \\
\hline Arthralgia/arthritis & 16 \\
\hline Folliculitis/pseudofolliculitis & 14 \\
\hline Erythema nodosum & 3 \\
\hline Furunculosis & 2 \\
\hline Paradoxical psoriasis by TNFi & 2 \\
\hline Deep venous thrombosis & 2 \\
\hline Ileitis & 2 \\
\hline Leg ulcers & 1 \\
\hline Unilateral anterior uveitis & 1 \\
\hline Neurobehçet & 1 \\
\hline Erythematosus and scaly skin lesions & 1 \\
\hline Fever & 1 \\
\hline
\end{tabular}

Abbreviations: $\mathrm{APR}=$ apremilast; $\mathrm{ADA}=$ adalimumab; $\mathrm{AZA}=$ azathioprine; $\mathrm{BD}$ : Behcet disease; $\mathrm{ETN}=$ etanercept; IFX = infliximab; IQR = interquartile range; MTX = methotrexate; NSAIDs = nonsteroidal antiinflammatory drugs; $\mathrm{SD}$ = standard deviation; $\mathrm{TCZ}$ = tocilizumab; TNFi = tumor necrosis factor inhibitors.

*Other treatments: cyclophosphamide (3), hydroxychloroquine (2), thalidomide (1), mycophenolate mofetil (1), golimumab (1), secukinumab (1).

Results are expressed as mean \pm standard deviation (SD), median [interquartile range: IQR] or as number (percentage: \%), depending on the variable analyzed.

This table should appear before the text section "Treatment before apremilast". Between lines 192 and 193. 
Number of patients $(n)$

Systemic Treatment before APR, $n$

Oral glucocorticoids

Colchicine

NSAIDs

MTX

AZA

Cyclosporine A

Dapsone

Sulfasalazine

ADA

IFX

TCZ

ETN

\section{1}

47

50

22

27

24

9

6

3

12

10

5

3

8

Other treatments*

Prednisone dose at APR onset, median [IQR], mg/d

10 [6-20.63]

Abbreviations: $A P R=$ apremilast; $A D A=$ adalimumab; $A Z A=$ azathioprine; $B D$ : Behcet disease; $E T N=$ etanercept; IFX = infliximab; IQR = interquartile range; MTX = methotrexate; NSAIDs = nonsteroidal antiinflammatory drugs; $\mathrm{SD}$ = standard deviation; TCZ = tocilizumab; TNFi = tumor necrosis factor inhibitors.

*Other treatments: cyclophosphamide (3), hydroxychloroquine (2), thalidomide (1), mycophenolate mofetil (1), golimumab (1), secukinumab (1).

Results are expressed as mean \pm standard deviation (SD), median [interquartile range: IQR] or as number (percentage: \%), depending on the variable analyzed.

This table should appear before the text section "Treatment before apremilast". Between lines 192 and 193. 
Number of patients (n)

Concomitant treatment, $\mathbf{n}$

Oral glucocorticoids

Colchicine

AZA

MTX

Hydroxychloroquine

Sulfasalazine

Dapsone

TCZ

ADA

IFX

Follow-up on APR therapy, mean (SD), months

Remission of orogenital ulcers, $n$ (\%)

Drug withdrawal, n (\%)

inefficacy, n (\%)

severe side-effects, n (\%)

others, n (\%)
51

28

25

7

5

4

4

1

2

1

1

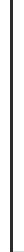
Abbreviations: $A P R=$ apremilast; $A D A$ = adalimumab; $A Z A$ = azathioprine; $B D$ : Behcet disease; $E T N=$ etanercept; IFX = infliximab; IQR = interquartile range; MTX = methotrexate; NSAIDs = nonsteroidal anti- inflammatory drugs; SD = standard deviation; TCZ = tocilizumab; TNFi = tumor necrosis factor inhibitors.

*Other treatments: cyclophosphamide (3), hydroxychloroquine (2), thalidomide (1), mycophenolate mofetil (1), golimumab (1), secukinumab (1).

Results are expressed as mean \pm standard deviation (SD), median [interquartile range: IQR] or as number (percentage: \%), depending on the variable analyzed.

This table should appear before the text section "Treatment before apremilast". Between lines 192 and 193.

\section{Treatment Before Apremilast}

Previously to APR, patients had received oral colchicine ( $n=50$, median dose [IQR] 1.5 [1-2] mg/day), oral glucocorticoids ( $n=47$, maximum median dose [IQR] 50 [20-60] mg/day, median dose at APR onset [IQR] $10[6.25-20] \mathrm{mg} /$ day) and NSAIDs $(n=22)$. 
In addition, all patients had received csDMARDs, and in many cases bDMARDs. The csDMARDs and dosages were the following: methotrexate $(\mathrm{MTX})(\mathrm{n}=27$, median dose [IQR] 15 [15-20] mg s.c. or p.o./week), azathioprine (AZA) ( $n=24$, median dose [IQR] 100 [100-150] mg p.o./day), cyclosporine $A(n$ $=9$, median dose [IQR] 200 [175-225] mg p.o./day), dapsone $(n=6$, median dose [IQR] 100 [100-175] mg p.o./day), cyclophosphamide ( $n=3$, i.v. pulses of $500 \mathrm{mg}$ every 15 days for 3 months), sulfasalazine (SSZ) ( $n=3,2$ g p.o./day), hydroxychloroquine (HCQ) ( $n=2,200 \mathrm{mg}$ p.o./day), thalidomide $(n=1,50 \mathrm{mg}$ p.o./day) and mycophenolate mofetil ( $n=1,3$ g p.o./day). The bDMARDs and dosages were the following: adalimumab (ADA) ( $n=12,40 \mathrm{mg}$ s.c. every other week), infliximab (IFX) ( $n=10,3-5 \mathrm{mg} / \mathrm{kg}$ i.v. at 0,2 and 6 weeks and then every $4-8$ weeks), etanercept $(n=3,50$ mg s.c. every week), tocilizumab (TCZ) $(n=5,8 \mathrm{mg} / \mathrm{kg}$ i.v. every 4 weeks), golimumab ( $n=1,50 \mathrm{mg}$ s.c. every 4 weeks) and secukinumab $(n=1,300 \mathrm{mg}$ s.c. every 4 weeks with previous loading dose).

\section{Apremilast In Monotherapy Or In Combined Therapy}

APR was given at standard dose of $30 \mathrm{mg}$ twice daily, with the usual dose escalation performed in 5 days. Apart from glucocorticoids, colchicine or NSAIDs, APR was given in combination with conventional $(n=16)$ or biologic $(n=2)$ or both conventional and biologic DMARDs $(n=2)$ in 20 patients (Table 1$)$.

An additional subanalysis comparing the efficacy of APR in monotherapy vs APR combined with csDMARDs and/or bDMARDs was carried out. However, there were not statistically significant differences in baseline characteristics and outcome (See Supplementary Table 1, Additional File 1).

\section{Outcomes Of Orogenital Ulcers And Other Clinical Manifestations}

Forty-four of 49 patients with available data at week 2 (89.8\%) experienced a rapid improvement of the orogenital ulcers. Maintained clinical improvement of orogenital manifestations was also observed in most cases (Table 2). As shown in the Supplementary Table 2, Additional File 2, the outcome of the orogenital ulcers was similar in patients treated with APR in monotherapy to those in whom APR was used in combination with conventional or biologic DMARDs. 
Table 2

Evolution of main symptoms and reduction of prednisone dose during apremilast treatment.

\begin{tabular}{|c|c|c|c|c|c|c|c|c|}
\hline & Baseline & $\begin{array}{l}\text { Week } \\
1-2 \\
n=49\end{array}$ & $\begin{array}{l}\text { Week } \\
4 \\
n=45\end{array}$ & $\begin{array}{l}\text { Month } \\
3 \\
n=38\end{array}$ & $\begin{array}{l}\text { Month } \\
6 \\
n=29\end{array}$ & $\begin{array}{l}\text { Month } \\
12 \\
n=13\end{array}$ & $\begin{array}{l}\text { Month } \\
18 \\
n=5\end{array}$ & $\begin{array}{l}\text { Month } \\
24 \\
n=2\end{array}$ \\
\hline \multicolumn{9}{|l|}{$\begin{array}{l}\text { Outcome of oral } \\
\text { and/or genital } \\
\text { ulcers n, }(\%)\end{array}$} \\
\hline Complete remission & & $\begin{array}{l}19 \\
(38.7)\end{array}$ & $\begin{array}{l}32 \\
(71.1)\end{array}$ & $\begin{array}{l}32 \\
(84.2)\end{array}$ & $\begin{array}{l}21 \\
(72.4)\end{array}$ & $\begin{array}{l}6 \\
(46.2)\end{array}$ & $3(60)$ & $\begin{array}{l}2 \\
(100)\end{array}$ \\
\hline Partial remission & & $\begin{array}{l}25 \\
(51)\end{array}$ & $\begin{array}{l}10 \\
(22.2)\end{array}$ & $2(5.3)$ & $\begin{array}{l}7 \\
(24.1)\end{array}$ & $\begin{array}{l}7 \\
(53.8)\end{array}$ & $2(40)$ & 0 \\
\hline No response & & $\begin{array}{l}5 \\
(10.3)\end{array}$ & $3(6.7)$ & $\begin{array}{l}4 \\
(10.5)\end{array}$ & $1(3.5)$ & 0 & 0 & 0 \\
\hline \multirow{2}{*}{$\begin{array}{l}\text { Dose of prednisone } \\
\text { (mg/day), median } \\
\text { [IQR] }\end{array}$} & 10 & 10 & $10^{\star}$ & $5^{\star}$ & $5^{\star}$ & 5 & 4.37 & NA \\
\hline & $\begin{array}{l}{[6.25-} \\
20]\end{array}$ & {$[5-15]$} & {$[5-15]$} & $\begin{array}{l}{[5-} \\
8.75]\end{array}$ & $\begin{array}{l}{[3.75-} \\
10]\end{array}$ & {$[2.5-5]$} & {$[2.5-5]$} & \\
\hline
\end{tabular}

Following APR use, a significant reduction of prednisone dose was achieved at month 3 . Consequently, the median prednisone dose was reduced from $10[5-20.63] \mathrm{mg} /$ day to $5[5-8.75] \mathrm{mg} / \mathrm{day}(p=0.018)$.

Efficacy of APR on clinical manifestations of BD different from orogenital ulcers is shown in Table $\mathbf{3}$ and Supplementary Table 3, Additional File 3. Overall, APR also yielded improvement of some non-aphthous manifestations such as the cutaneous follicular and intestinal manifestations. However, the effect on musculoskeletal manifestations was variable.

Due to technical limitations, Table 3 is provided in the Supplementary Files sectin.

During the follow-up period, the median serum CRP fell from $0.5[0.13-1.48]$ to 0.35 [0.12-0.52] $\mathrm{mg} / \mathrm{dL}$ and the median ESR from 10 [4.5-20.5] to 9 [2-33.7] $\mathrm{mm} / 1$ st hour.

\section{Adverse Events}

After an mean follow-up of $8.5 \pm 6.9$ months, 31 patients developed side-effects, most of them mild and within the first 3 months from the onset of APR: nausea $(n=12)$, diarrhea $(n=11)$, dyspepsia $(n=10)$, headache $(n=9)$, abdominal pain $(n=4)$, loss of appetite $(n=4)$, weight loss $(n=3)$, halitosis $(n=1)$, dry mouth $(n=1)$, sinusitis $(n=1)$, palpitations $(n=1)$ and/or depression $(n=1)$. Due to this, 6 of them had to reduce the dose of APR to $30 \mathrm{mg} /$ day.

APR was discontinued in 11 patients due to lack of effect $(n=5)$, gastrointestinal adverse events $(n=3)$, desire of pregnancy $(n=1)$, persistent erythema nodosum $(n=1)$ and development of neurological 
involvement $(n=1)$. Therefore, the retention rate of APR during follow-up was $78.4 \%$.

Figure 1 shows a flow-chart summarizing the features of the 51 patients with refractory orogenital ulcers on APR, including non-aphthous manifestation, combined treatment and adverse events.

\section{Discussion}

The results from the present study indicate that in clinical practice APR yields a rapid and maintained improvement of BD's refractory orogenital manifestations. This is of potential relevance since oral and genital ulcers are the most representative manifestations of $\mathrm{BD}[8,23,25]$.

Due to the different phenotypes of the disease and the lack of consensual standards of care, BD treatment remains to be a challenge. The use of therapies is in many cases based on a few randomized clinical trials, singular case reports or small case series [26, 27]. European League Against Rheumatism (EULAR) group has published an update of recommendations for the management of BD depending on the domain(s) affected in each patient, providing a more individualized therapeutic approach [9].

Several therapeutic agents have been used for orogenital aphthous ulcers with variable results [28]. There is general agreement on the use of topical agents such as chlorhexidine, lidocaine gel and glucocorticoid preparations for oral mucosal involvement. Alpsoy et al. described effectiveness of sucralfate suspension for oral and genital ulcers [29]. Colchicine remains as the first-line systemic agent used for orogenital features of BD because of its inhibition of neutrophil chemotaxis [26, 30,31]. This drug has proved to be useful for the treatment of erythema nodosum, genital ulcers of women and arthritis. However, there is no full evidence on its efficacy in oral ulcers [26, 32-35]. Kaneko et al. [36] reported that minocycline can reduce the frequency of oral ulcers, erythema nodosum and papulopustular lesions in BD patients as well as the production of pro-inflammatory cytokines by BD-peripheral blood mononuclear cells stimulated with streptococcal antigen. AZA is another drug used to avoid the development of mucocutaneous lesions of BD [37]. Thalidomide has shown efficacy for the treatment of oral and genital ulcers and papulopustular lesions in patients with BD. Nevertheless, maintenance treatment is frequently required to prevent the development of recurrences [26,31,38-41], which together with the possibility of the appearance of nodular lesions and worsening of erythema nodosum, as well as the serious adverse events that this drug can cause, limit its use. Cyclosporin is another agent relegated to the background, due to its adverse events $[26,31]$. Sharquie et al. showed that dapsone was effective for the treatment of mucocutaneous lesions of BD in a double blind, placebo-controlled clinical trial [42]. With respect to TNFi, etanercept is the only drug assessed in a randomized controlled clinical trial that proved efficacy to suppress many mucocutaneous features, leading to a decrease in the frequency of appearance of oral ulcers and papulopustular lesions $[4,26]$. There are also case reports of successful treatment of genital ulcers with adalimumab $[26,43]$. Interferon (IFN) a has been used in mucocutaneous lesions with contradictory results and a high rate of adverse events [44-46]. A few studies suggest that anakinra, secukinumab and ustekinumab may be useful in the treatment of orogenital ulcers of BD [47-50]. 
APR is an oral small molecule which inhibits PDE-4 and increases the levels of intracellular cyclic AMP, modulating several inflammatory pathways $[10,11]$. A randomized phase II trial that included 111 patients with BD showed that patients treated with APR had a significant reduction in the number of oral ulcers at 12 weeks [15]. However, this trial did not provide enough information on previous therapies and extra-mucocutaneous manifestations. A recent phase III trial has shown significant improvement of pain and number of oral ulcers in 104 patients treated with APR, resolution maintained over 12 weeks and in many cases also resolution of genital ulcers [16]. Because of that, the U.S. FDA has recently approved APR for BD ulcers (www.fda.gov). However, in these trials the patients with major organ involvement of $\mathrm{BD}$ or comorbidities were excluded and full information on former therapies before APR was not available. Also, the time of follow-up was not very long. Moreover, to the best of our knowledge, both trials used APR in monotherapy and they did not assess the effect of APR on extra-mucocutaneous manifestations of $B D[15,16]$. Thus, the strict criteria required for inclusion may constitute a limitation at the time of considering APR in real-life patients.

In our study, APR achieved a rapid and sustained response of mucocutaneous ulcers in patients refractory to several systemic drugs, including biologic therapy. Adverse events were mild and most of them well tolerated. According to our findings, APR may be combined with either with csDMARDs and/or bDMARDs with acceptable safety profile. Nevertheless, we are aware of potential limitations of our study, mainly due to its retrospective nature.

\section{Conclusion}

In conclusion, we report real life data showing that APR therapy is effective in highly refractory BD orogenital ulcers.

\section{Abbreviations}

APR: apremilast; BD: Behçet's disease; PDE-4: phosphodiesterase-4; tsDMARDs: targeted synthetic disease-modifying antirheumatic drugs; bDMARDs: biological disease-modifying antirheumatic drugs; csDMARDs: conventional synthetic disease-modifying antirheumatic drugs; RCTs: randomized clinical trials; FDA: Food and Drug Administration; NSAIDs: non-steroidal anti-inflammatory drugs; ISGBD: International Study Group for BD; CRP: C-reactive protein; ESR: erythrocyte sedimentation rate; SD: standard deviation; IQR: interquartile range; TNFi: TNFa-inhibitors; MTX: methotrexate; AZA: azathioprine; SSZ: sulfasalazine; HCQ: hydroxychloroquine; ADA: adalimumab; IFX: infliximab; TCZ: tocilizumab; EULAR: European League Against Rheumatism; IFN: interferon.

\section{Declarations}

\section{Ethics approval and consent to participate}


The study was conducted in accordance with the Declaration of Helsinki, and the protocol was approved by the Ethics Committee of clinical research of Cantabria, Spain (2018.100). All patients gave their informed consent for inclusion in the study.

\section{Consent for publication}

This manuscript does not contain any individual person's data.

\section{Availability of data and materials}

The datasets used and/or analysed during the current study are available from the corresponding author on reasonable request.

\section{Competing interests}

BA-M received grants/research supports from Kern Pharma, AbbVie, Pfizer, Celgene and GSK.

JLM-V received grants/research supports from AbbVie, Pfizer and Celgene.

JG received grants/research supports from Abbvie, Bristol, Pfizer, Janssen, Roche, MSD, Gebro, Sanofi and Amgen.

GE received grants/research supports from Actelion, Janssen, GSK, Boehringer and Amgen.

CM received grants/research supports from Lilly, Roche, Abbvie, Pzifer, Gebro, Novartis and Sanofi, and had consultation fees/participation in company sponsored speaker's bureau from Bristol, Pzifer, Lilly, GSK, Celgene and Amgen.

TP-S had nothing to disclose.

MM-M received grants/research supports from Pfizer, Janssen, Stada and Sandoz.

ED-A had nothing to disclose.

MDG-A had nothing to disclose.

EM had nothing to disclose.

IC had nothing to disclose.

FS had nothing to disclose.

JC-A had consultation fees/participation in company sponsored speaker's bureau from Celgene. IdIM had nothing to disclose.

FO-S had nothing to disclose. 
JAR-I had nothing to disclose.

AP-G had nothing to disclose.

SH had nothing to disclose.

AO had consultation fees/participation in company sponsored speaker's bureau from Celgene.

AP-E had nothing to disclose.

CD had nothing to disclose.

JJA had nothing to disclose.

AY had nothing to disclose.

AMF had nothing to disclose.

JN had nothing to disclose.

IF had consultation fees/participation in company sponsored speaker's bureau from Celgene.

AIT had nothing to disclose.

SRY had nothing to disclose.

PT had nothing to disclose.

SO had consultation fees/participation in company sponsored speaker's bureau from Celgene.

IR received grants/research supports from Celgene as principal investigator of PREVAIL study on apremilast in psoriasic arthritis.

$\mathrm{JL}$ attended conferences with Novartis, Abbvie, Roche, MSD, Bristol-Myers Squibb, Lilly, Pfizer and Celgene, and participated in courses and lectures sponsored by Novartis, MSD, Abbvie, Celgene and Gebro Pharma.

VC-R had consultation fees/participation in company sponsored speaker's bureau from Abbvie, Lilly, MSD, UCB Pharma and Celgene.

CG-V had nothing to disclose.

SC had nothing to disclose.

JLH had nothing to disclose. 
MAG-G received grants/research supports from Abbott, MSD and Roche, and had consultation fees/participation in company sponsored speaker's bureau from Abbott, Pfizer, Roche and MSD.

RB received grants/research supports from Abbott, MSD and Roche, and had consultation fees/participation in company sponsored speaker's bureau from Abbott, Pfizer, Roche, Bristol-Myers, Janssen and MSD.

\section{Funding}

There was no funding for this study.

\section{Authors' contributions}

BA-M, JL-MV, JL and RB have made substantial contributions to the conception and design of the work. All authors have contributed to the acquisition, analysis and interpretation of the data and have drafted the work. JL, SC, MAG-G and RB have substantively revised the work. All authors have agreed to be personally accountable for the author's own contributions and to ensure that questions related to the accuracy or integrity of any part of the work are appropriately investigated, resolved, and the resolution documented in the literature. Submitted version of the manuscript has been approved by all authors.

\section{Acknowledgements}

The authors acknowledge all the members of the participating hospitals.

\section{References}

1. McGonagle D, McDermott MF. A proposed classification of the immunological diseases. PLoS Med. 2006;3:e297.

2. Jennette JC, Falk RJ, Bacon PA, Basu N, Cid MC, Ferrario F, et al. 2012 revised International Chapel Hill Consensus Conference Nomenclature of Vasculitides. Arthritis Rheum. 2013;65:1-11.

3. Hatemi G, Silman A, Bang D, Bodaghi B, Chamberlain AM, Gul A, et al. EULAR recommendations for the management of Behçet disease. Ann Rheum Dis. 2008;67:1656-62.

4. Hatemi G, Silman A, Bang D, Bodaghi B, Chamberlain AM, Gul A, et al. Management of Behcet disease: a systematic literature review for the European League Against Rheumatism evidence-based recommendations for the management of Behcet disease. Ann Rheum Dis. 2009;68:1528-34.

5. Ozguler Y, Hatemi G, Yazici H. Management of Behçet's syndrome. Curr Opin Rheumatol. 2014;26:285-91.

6. Alibaz-Oner F, Sawalha AH, Direskeneli H. Management of Behçet's disease. Curr Opin Rheumatol. 2018;30:238-42.

7. Hasan Yazici E, Seyahi G, Hatemi, Yazici Y. Behçet syndrome: a contemporary view. Nat Rev Rheumatol. 2018;14:107-19. 
8. Melikoglu M, Melikoglu MA. What affects the quality of life in patients with Behcet's disease? Acta Reumatol Port. 2014;39:46-53.

9. Hatemi G, Christensen R, Bang D, Bodaghi B, Celik AF, Fortune F, et al. 2018 update of the EULAR recommendations for the management of Behçet's syndrome. Ann Rheum Dis. 2018;77:808-18.

10. Man HW, Schafer P, Wong LM, Patterson RT, Corral LG, Raymon H, et al. Discovery of (S)-N-[2-[1-(3ethoxy-4-methoxyphenyl)-2-methanesulfonylethyl]-1,3-dioxo-2,3-dihydro-1H-isoindol-4-yl] acetamide (apremilast), a potent and orally active phosphodiesterase 4 and tumor necrosis factor-alpha inhibitor. J Med Chem. 2009;52:1522-4.

11. Schafer PH, Parton A, Capone L, Cedzik D, Brady H, Evans, et al. Apremilast is a selective PDE4 inhibitor with regulatory effects on innate immunity. Cell Signal. 2014;26:2016-29.

12. Boleto G, Kanagaratnam L, Dramé M, Salmon JH. Safety of combination therapy with two bDMARDs in patients with rheumatoid arthritis: A systematic review and meta-analysis. Semin Arthritis Rheum. 2019;49:35-42.

13. Martin K, Bégaud B, Atry P, Miremont-Salamé G, Fourrier A, Moore N. Differences between Clinical trials and postmarketing use. $\mathrm{Br} \mathrm{J}$ Clin Pharmacol. 2004;57:86-92.

14. Stuart EA, Cole SR, Bradshaw CP, Leaf PJ. The use of propensity scores to assess the generalizability of results from randomized trials. J R Stat Soc Ser A Stat Soc. 2011;174:369-86.

15. Hatemi G, Melikoglu M, Tunc R, Korkmaz C, Turgut Ozturk B, Mat C, et al. Apremilast for Behçet's Syndrome-A Phase 2, Placebo-Controlled Study. N Engl J Med. 2015;372:1510-8.

16. Hatemi G, Mahr A, Ishigatsubo Y, Song YW, Takeno M, Kim D, et al. Trial of Apremilast for Oral Ulcers in Behçet's Syndrome. N Engl J Med. 2019;381:1918-28.

17. Criteria for diagnosis of Behcet's disease International Study Group for. Behcet's Disease Lancet. 1990;335(8697):1078-80.

18. Riancho-Zarrabeitia L, Calvo-Río V, Blanco R, Mesquida M, Adan AM, Herreras JM, et al. Anti-TNF-a therapy in refractory uveitis associated with sarcoidosis: Multicenter study of 17 patients. Semin Arthritis Rheum. 2015;45:361-8.

19. Calvo-Río V, de la Hera D, Beltrán-Catalán E, Blanco R, Hernandez M, Martínez-Costa L, et al. Tocilizumab in uveitis refractory to other biologic drugs: a study of 3 cases and a literature review. Clin Exp Rheumatol. 2014;32(4 Suppl 84):54-7.

20. Fernández-Díaz C, Loricera J, Castañeda S, López-Mejías R, Ojeda-García C, Olivé A, et al. Abatacept in patients with rheumatoid arthritis and interstitial lung disease: A national multicentre study of 63 patients. Semin Arthritis Rheum. 2018;48:22-7. doi:10.1016/j.semarthrit.2017.12.012.

21. Atienza-Mateo B, Martín-Varillas JL, Calvo-Río V, Demetrio-Pablo R, Beltrán E, Sánchez-Bursón J, et al. Comparative study of infliximab versus adalimumab in refractory uveitis due to Behçet's disease. National multicenter study of 177 cases. Arthritis Rheumatol. 2019;71:2081-9. doi:10.1002/art.41026.

22. Calderón-Goercke M, Loricera J, Aldasoro V, Castañeda S, Villa I, Humbría A, et al. Tocilizumab in giant cell arteritis. Observational, open-label multicenter study of 134 patients in clinical practice. 
Semin Arthritis Rheum. 2019;49:126-35.

23. Zeidan MJ, Saaduoun D, Garrido M, Klatzmann D, Six A, Caccoub P. Behçet's disease physiopathology: a contemporary review. Auto Immun Highlights. 2016;7:4.

24. Mendes D, Correia M, Barbedo M, Vaio T, Mota M, Gonçalves O, et al. Behçet's disease- a contemporary review. J Autoimmun. 2009;32:178-88.

25. Krause I, Rosen Y, Kaplan I, Milo G, Guedj D, Molad Y, et al. Recurrent aphthous stomatitis in Behcet's disease: clinical features and correlation with systemic disease expression and severity. $\mathrm{J}$ Oral Pathol Med. 1999;28:193-6.

26. Saleh Z, Arayssi T. Update on the therapy of Behçet disease. Ther Adv Chronic Dis. 2014;5:112-34.

27. Esatoglu SN, Hatemi G. Update on the treatment of Behçet's syndrome. Intern Emerg Med. 2019;14:661-75.

28. Vitale A, Rigante D, Lopalco G, Emmi G, Bianco MT, Galeazzi M, et al. New therapeutic solutions for Behçet's syndrome. Expert Opin Investig Drugs. 2016;25:827-40.

29. Alpsoy E, Er H, Durusoy C, Yilmaz E. The use of sucralfate suspension in the treatment of oral and genital ulceration of Behçet disease: a randomized, placebo-controlled, double-blind study. Arch Dermatol. 1999;135:529-32.

30. Alpsoy E. Behçet's disease: A comprehensive review with a focus on epidemiology, etiology and clinical features, and management of mucocutaneous lesions. J Dermatol. 2016;43:620-32.

31. Lin P, Liang G. Behçet disease: recommendation for clinical management of mucocutaneous lesions. J Clin Rheumatol. 2006;12:282-6.

32. Aktulga E, Altac M, Muftuoglu A, Ozyazgan $Y$, Pazarli $H$, Tuzun $Y$, et al. A double-blind study of colchicine in Behçet's disease. Haematologica. 1980;65:399-402.

33. Yurdakul S, Mat C, Tüzün Y, Ozyazgan Y, Hamuryudan V, Uysal O, et al. A double-blind trial of colchicine in Behçet's síndrome. Arthritis Rheum. 2001;44:2686-92.

34. Calguneri M, Kiraz S, Ertenli I, Benekli M, Karaarslan Y, Celik I. The effect of prophylactic penicillin treatment on the course of arthritis episodes in patients with Behçet's disease. A randomized clinical trial. Arthritis Rheum. 1996;39:2062-5.

35. Mazzoccoli G, Matarangolo A, Rubino R, Inglese M, De Cata A. Behçet syndrome: from pathogenesis to novel therapies. Clin Exp Med. 2016;16:1-12.

36. Kaneko F, Oyama N, Nishibu A. Streptococcal infection in the pathogenesis of Behçet's disease and clinical effects of minocycline on the disease symptoms. Yonsei Med J. 1997;38:444-54.

37. Yazici H, Pazarli H, Barnes CG, Tuzun Y, Ozyazgan Y, Silman A, et al. A controlled trial of azathioprine in Behçet's syndrome. N Engl J Med. 1990;322:281-5.

38. Hamuryudan V, Mat C, Saip S, Ozyazgan Y, Siva A, Yurdakul S, et al. Thalidomide in the treatment of the mucocutaneous lesions of the Behçet syndrome. A randomized, double-blind, placebo-controlled trial. Ann Intern Med. 1998;128:443-50. 
39. Gardner-Medwin JM, Smith NJ, Powel RJ. Clinical experience with thalidomide in the management of severe oral and genital ulceration in conditions such as Behçet's disease: use of neurophysiological studies to detect thalidomide neuropathy. Ann Rheum Dis. 1994;53:828-32.

40. Saylan T, Saltik I. Thalidomide in the treatment of Behçet's syndrome. Arch Dermatol. 1982;118:536.

41. Hamza MH. Treatment of Behçet's disease with thalidomide. Clin Rheumatol. 1986;5:365-71.

42. Sharquie KE, Najim RA, Abu-Raghif AR. Dapsone in Behçet's disease: a double-blind, placebocontrolled, cross-over study. J Dermatol. 2002;29:267-79.

43. Vitale A, Emmi G, Lopalco G, Gentileschi S, Silvestri E, Fabiani C, et al. Adalimumab effectiveness in Behçet's disease: short and long-term data from a multicenter retrospective observational study. Clin Rheumatol. 2017;36:451-5.

44. Boyvat A, Sisman-Solak C, Gurler A. Long-term effects of interferon a2a treatment in Behçet's disease. Dermatology. 2000;201:40-3.

45. Alpsoy E, Durusoy C, Yilmaz E, Ozgurel Y, Ermis O, Yazar S, et al. Interferon a-2a in the treatment of Behçet disease: a randomized placebo-controlled and double-blind study. Arch Dermatol. 2002;138:467-71.

46. Keskin Y, Seyahi E, Poyraz C, Ugurlu S, Ozyazgan Y, Yazici H. Interferon alfa-associated depression in patients with Behcet's syndrome: a prospective controlled study. Clin Exp Rheumatol. 2014;32(4 Suppl 84):175.

47. Grayson PC, Yazici Y, Merideth M, Sen HN, Davis M, Novakovich E, et al. Treatment of mucocutaneous manifestations in Behçet's disease with anakinra: a pilot open-label study. Arthritis Res Ther. 2017;19:69.

48. Lopalco G, Fabiani C, Venerito V, Lapadula G, lannone F, Cantarini L. Ustekinumab efficacy and safety in mucocutaneous multi-refractory Behçet's disease. Clin Exp Rheumatol. 2017;35:130-1.

49. Mirouse A, Barete S, Monfort JB, Resche-Rigon M, Bouyer AS, Comarmond C, et al. Ustekinumab for Behçet's disease. J Autoimmun. 2017;82:41-6.

50. Di Scala G, Bettiol A, Cojan RD, Finocchi M, Silvestri E, Emmi G. Efficacy of the anti-IL 17 secukinumab in refractory Behçet's syndrome: A preliminary study. J Autoimmun. 2019;97:108-13.

\section{Figures}




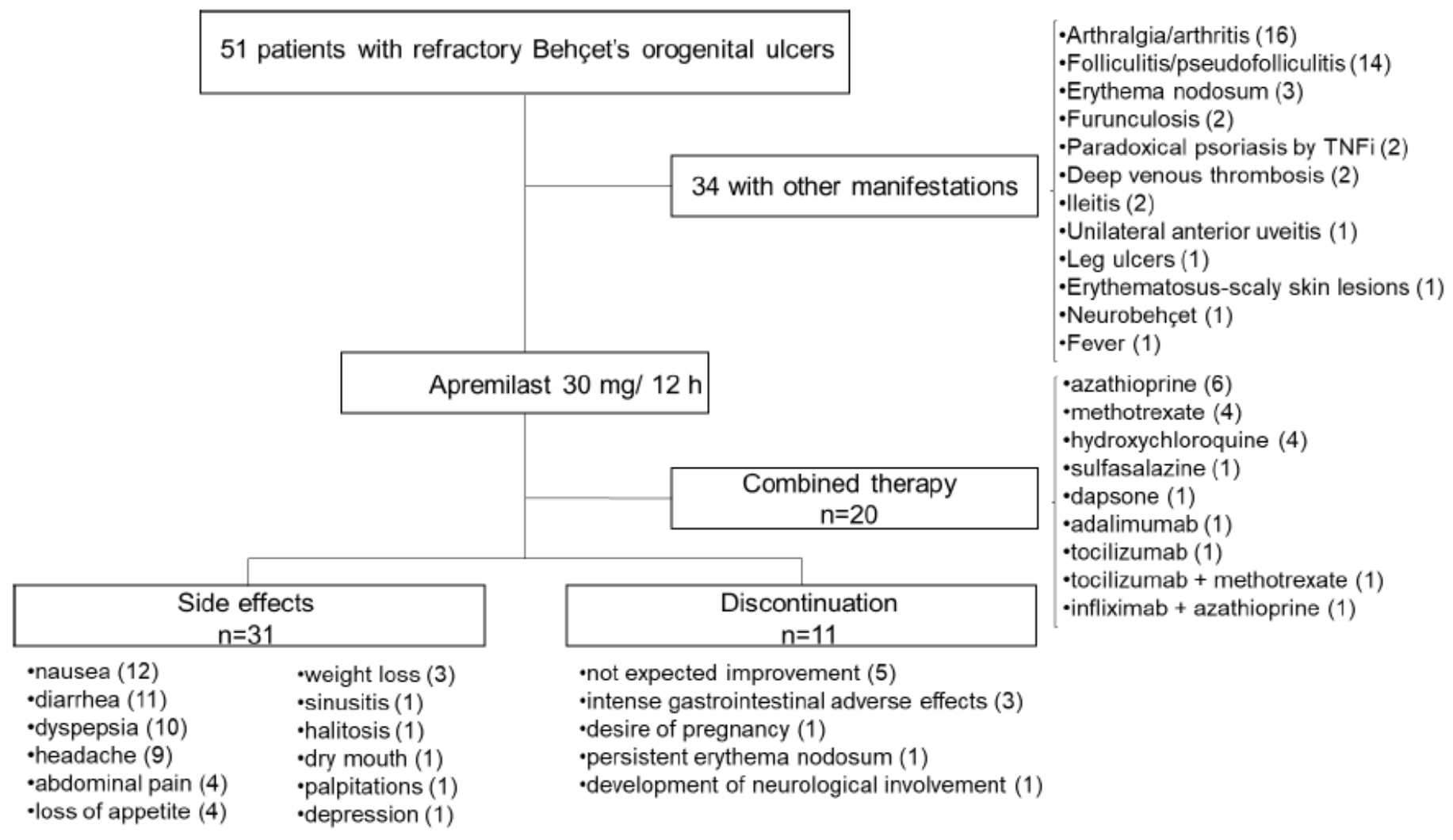

\section{Figure 1}

Flow-chart summarizing the features of 51 patients with refractory orogenital ulcers receiving apremilast therapy.

\section{Supplementary Files}

This is a list of supplementary files associated with this preprint. Click to download.

- Additionalfile2.docx

- Additionalfile1.docx

- Additionalfile3.docx

- Table3.docx 